\title{
Heat Transfer Enhancement of Laminar Nanofluids Flow in a Circular Tube Fitted with Parabolic-Cut Twisted Tape Inserts
}

\author{
Sami D. Salman, ${ }^{1,2}$ Abdul Amir H. Kadhum, ${ }^{1}$ Mohd S. Takriff, ${ }^{1}$ and Abu Bakar Mohamad ${ }^{1}$ \\ ${ }^{1}$ Department of Chemical and Process Engineering, Faculty of Engineering and Built Environment, Universiti Kebangsaan Malaysia, \\ 43600 Bangi, Selangor, Malaysia \\ ${ }^{2}$ Biochemical Engineering Department, Al-khwarizmi College of Engineering, University of Baghdad, Baghdad 47024, Iraq
}

Correspondence should be addressed to Sami D. Salman; sami.albayati@gmail.com

Received 16 August 2013; Accepted 5 December 2013; Published 30 January 2014

Academic Editors: L. D. S. Coelho and M. Q. Fan

Copyright (C) 2014 Sami D. Salman et al. This is an open access article distributed under the Creative Commons Attribution License, which permits unrestricted use, distribution, and reproduction in any medium, provided the original work is properly cited.

\begin{abstract}
Numerical investigation has been carried out on heat transfer and friction factor characteristics of copper-water nanofluid flow in a constant heat-fluxed tube with the existence of new configuration of vortex generator using Computational Fluid Dynamics (CFD) simulation. Two types of swirl flow generator: Classical twisted tape (CTT) and Parabolic-cut twisted tape (PCT) with a different twist ratio $(y=2.93,3.91$ and 4.89$)$ and different cut depth $(w=0.5,1.0$ and $1.5 \mathrm{~cm})$ with $2 \%$ and $4 \%$ volume concentration of $\mathrm{CuO}$ nanofluid were used for simulation. The effect of different parameters such as flow Reynolds number, twist ratio, cut depth and nanofluid were considered. The results show that the enhancement of heat transfer rate and the friction factor induced by the Classical (CTT) and Parabolic-cut (PCT) inserts increases with twist ratio and cut depth decreases. The results also revealed that the heat transfer enhancement increases with an increase in the volume fraction of the $\mathrm{CuO}$ nanoparticle. Furthermore, the twisted tape with twist ratio $(y=2.93)$ and cut depth $w=0.5 \mathrm{~cm}$ offered $10 \%$ enhancement of the average Nusselt number with significant increases in friction factor than those of Classical twisted tape.
\end{abstract}

\section{Introduction}

The applications of heat transfer augmentation techniques can significantly increase the performance of heat exchanger, leading to the reduction of heat exchanger size as well as operating cost. The augmentation is classified into three main techniques, namely, active, passive, and compound. The active techniques require an external force such as electric field, acoustic, or surface vibration. The passive technique involves fluid additives, special surface geometries, or swirl flow devices, that is, Twisted tape inserts. On the other hand, the compound techniques are made by a combination between two or more passive and/or active techniques. Several experimental studies on heat transfer augmentation techniques using twisted tape have been reported in the literature [1-15], as well as theoretical studies using CFD modeling. Kharat et al. [16] developed the new correlation of heat transfer coefficient between concentric helical coils of a heat exchanger which depended on experimental work and CFD simulation. Fluent 6.3.26 has been used to improve the heat transfer coefficient correlation for the flue gas side to optimize the gap between concentric coils. Pathipakka and Sivashanmugam [17] proposed CFD simulation of the heat transfer characteristics of a $\mathrm{Al}_{2} \mathrm{O}_{3}$ nanofluid in a circular tube fitted with helical twist inserts under constant heat flux using Fluent version 6.3.26 in a laminar flow. The $\mathrm{Al}_{2} \mathrm{O}_{3}$ nanoparticles in water at different concentrations $(0.5 \%, 1.0 \%$, and $1.5 \%)$ and helical twist inserts with different twist ratios $(y=2.93,3.91$, and 4.89) were used for the simulation. The data obtained by simulation was compared with the literature value of water for plain tube helical tape inserts. Salman et al. [18] reports an application of a mathematical model of the heat transfer enhancement and friction factor characteristics of water in constant heat-fluxed tube fitted with elliptical cut twisted tape inserts using FLUENT version 6.3.26. Two types of swirl flow generator: Classical and elliptical cut twisted tape with twist ratio $(y=2.93,3.91,4.89)$ and different cut depths $(w=0.5,1,1.5 \mathrm{~cm})$ were used for simulation. The results elaborated that the enhancement of heat transfer rate and the friction factor induced by elliptical cut twisted tape inserts 
TABLE 1: Thermophysical properties of water and $\mathrm{CuO}$ nanofluids.

\begin{tabular}{lcccc}
\hline \multirow{2}{*}{ Fluid } & & \multicolumn{2}{c}{ Nanofluids properties } & Thermal conductivity \\
& Density $\left(\mathrm{kg} / \mathrm{m}^{3}\right)$ & Specific heat $(\mathrm{J} / \mathrm{kg} \mathrm{K})$ & 0.6096 & \multicolumn{1}{c}{ Viscosity $($ Pa s) } \\
\hline Water & 997 & 4180 & 17.6 & 0.000693 \\
$\mathrm{CuO}$ & 6500 & 533 & 0.6797 & 0.00116 \\
Water $+2 \% \mathrm{CuO}$ & 1017.1 & 3751.9 & 0.7163 & 0.00147 \\
Water $+4 \% \mathrm{CuO}$ & 1217.1 & 3401.1 & & 0 \\
\hline
\end{tabular}

TABLE 2: Thermophysical properties of the materials.

\begin{tabular}{lccc}
\hline Materials & $\begin{array}{c}\text { Density } \\
\mathrm{Kg} / \mathrm{m}^{3}\end{array}$ & $\begin{array}{c}\text { Specific heat } \\
\mathrm{J} / \mathrm{kg} \mathrm{K}\end{array}$ & $\begin{array}{c}\text { Thermal } \\
\text { conductivity W/m K }\end{array}$ \\
\hline Steel & 8030 & 502.48 & 16.27 \\
Aluminium & 2719 & 871 & 202.4 \\
\hline
\end{tabular}

increase with Reynolds number and decrease with twist ratio. In addition, the results show that the elliptical cut twisted tape with twist ratio $(y=2.93)$ and cut depth $(w=0.5 \mathrm{~cm})$ offered higher heat transfer rate with significant increases in friction factor. Salman et al. [19] numerically studied heat transfer of water in a uniformly heated circular tube fitted with V-cut twisted tape inserts in laminar flow using FLUENT version 6.3.26. Classical and elliptical cut twisted tape with twist ratio $(y=2.93,3.91,4.89)$ and different cut depths $(w=0.5,1$, $1.5 \mathrm{~cm}$ ) were employed for the simulation. The results show that the V-cut twisted tape with twist ratio $(y=2.93)$ and cut depth $(w=0.5 \mathrm{~cm})$ present a maximum heat transfer rate with significant increases in friction factor.

In the present work, a numerical investigation of heat transfer enhancement in a tube induced by new configuration of vortex generator (Parabolic-cut twist tape) with $2 \%$ and $4 \%$ volume fractions of $\mathrm{CuO}$ nanofluid is reported using CFD simulation. The result obtained by this configuration offered about $10 \%$ enhancement of the Nusselt number with significant increases in friction factor than those of Classical twisted tape.

\section{Technical Details}

2.1. Physical Models. The configuration of the Parabolic-cut twisted tape (PCT) insert is shown in Figure 1. Aluminium tape of $0.08 \mathrm{~cm}$ thickness and $2.45 \mathrm{~cm}$ width is uniformly winding over a length of $7.5,10$, and $12.5 \mathrm{~cm}$ to produce twist ratios of $2.93,3.91$, and 4.89 . The twist ratio " $y$ " is defined as the ratio of the length of one full twist $\left(360^{\circ}\right)$ to the tape width. Three cut depth $(w=0.5,1$, and $1.5 \mathrm{~cm})$ is used for each twisted tape to produce Parabolic-cut twisted tape.

Steel tube with a diameter $(D)$ of $2.54 \mathrm{~cm}$ and length $(L)$ of $180 \mathrm{~cm}$ is used as test section, Water and $\mathrm{CuO}$ nanoparticles $(d p=29 \mathrm{~nm})$ are selected as the working fluid. The thermophysical properties of fluid and materials used for simulation are shown in Tables 1 and 2.

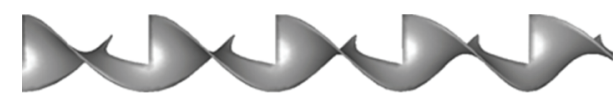

FIgURe 1: Parabolic-cut twisted insert.

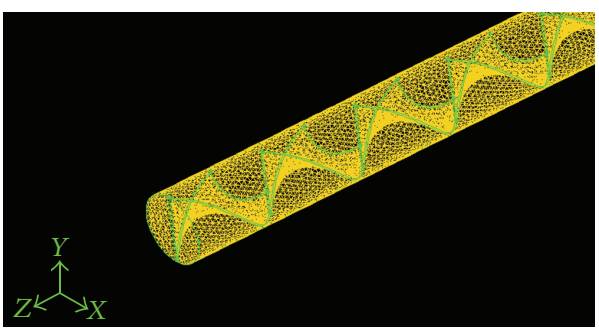

FIGURE 2: Grid of Parabolic-cut twisted tape (PCT) insert.

2.2. Thermophysical Properties of Nanofluids. The thermophysical properties of nanofluids used in this study were obtained using the following equations [20]:

$$
\begin{gathered}
\rho_{\mathrm{nf}}=(1-\phi) \rho_{f}+\phi \rho_{\mathrm{np}}, \\
(\rho C p)_{\mathrm{nf}}=(1-\phi)(\rho C p)_{f}+\phi(\rho C p)_{\mathrm{np}}
\end{gathered}
$$

where $\rho_{f}$ and $\rho_{\mathrm{np}}$ are the mass densities of the based fluid and the solid nanoparticles, $\phi$ nanoparticle volume concentration, and $(\rho C p)_{f}$ and $(\rho C p)_{n p}$ are heat capacities of the based fluid and the solid nanoparticles.

The effective thermal conductivity can be obtained by using the following mean empirical correlation [20]:

$$
\begin{gathered}
K_{\text {eff }}=K_{\text {Static }}+K_{\text {Brownian }}, \\
K_{\text {Static }}=K_{f}\left[\frac{\left(K_{\mathrm{np}}+2 K_{f}\right)-2 \phi\left(K_{f}-K_{\mathrm{np}}\right)}{\left(K_{\mathrm{np}}+2 K_{f}\right)+\phi\left(K_{f}+K_{\mathrm{np}}\right)}\right], \\
K_{\text {Brownian }}=5 * 10^{4} \beta \phi \rho_{f} C p_{f} \sqrt{\frac{K T}{2 \rho_{\mathrm{np}} R_{\mathrm{np}}}} f(T, \phi),
\end{gathered}
$$

where $\beta=9.881(100 \phi)^{-0.9446}$ for $\mathrm{CuO}$ nanoparticle, $k=$ $1.3807 * 10^{-23} \mathrm{~J} / \mathrm{K}$ (Boltzmann constant), and $f(T, \phi)=$ $\left(2.8217 * 10^{-2} \phi+3.917 * 10^{-3}\right)\left(T / T_{0}\right)+\left(-3.669 * 10^{-2} \phi-\right.$ $\left.3.391123 * 10^{-3}\right)$. 


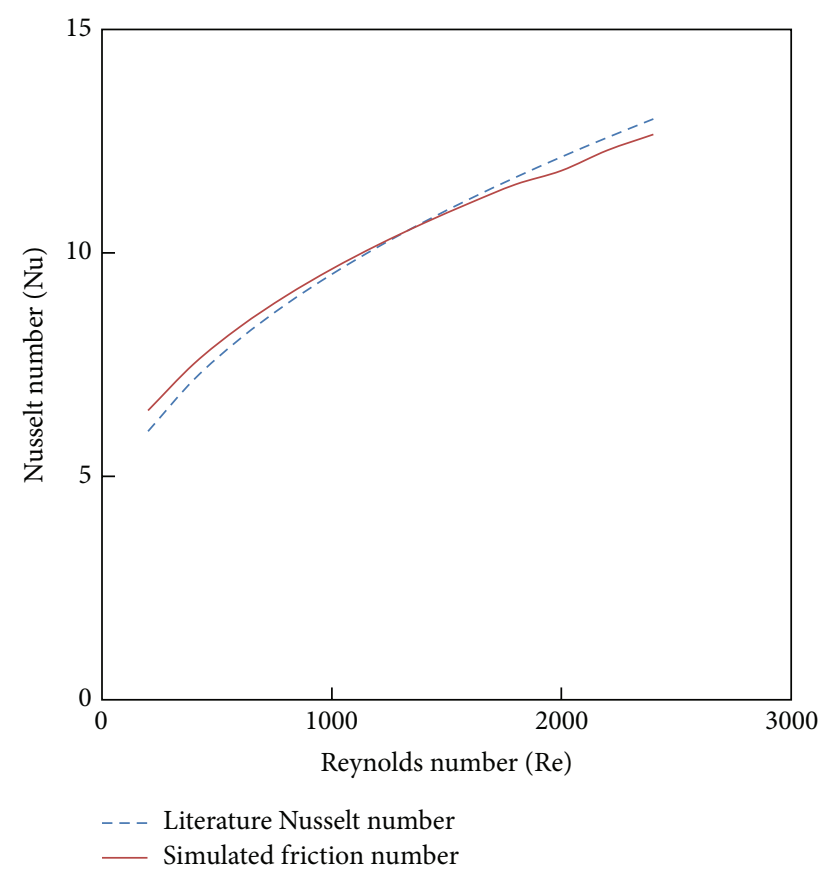

FIgURE 3: Plain tube simulated Nusselt number versus literature value.

The effective viscosity can be obtained by using the following mean empirical correlation [21]:

$$
\begin{gathered}
\mu_{\mathrm{eff}}=\mu_{f} * \frac{1}{\left(1-34.87(d p / d f)^{-0.3} * \phi^{1.03}\right)}, \\
d f=\left[\frac{6 M}{N \pi \rho_{f_{0}}}\right],
\end{gathered}
$$

where $M$ is the molecular weight of base fluid, $N$ is the Avogadro number $=6.022 * 10^{23} \mathrm{~mol}^{-1}$, and $\rho_{f_{0}}$ is the mass density of the based fluid calculated at temperature $T_{0}=$ $293 \mathrm{~K}$.

\section{CFD Simulation}

3.1. Geometry Creation and Grid Arrangement. The geometry and the gird (mesh) were generated using GAMBIT and FLUENT as CFD solver to handle this grid. The geometry of twist tape inserts is made by winding uniformly a strip of $0.08 \mathrm{~cm}$ thickness and $2.45 \mathrm{~cm}$ width using a perpendicular sweep face option. The angle of twist is $360^{\circ}$ over a length of $7.5,10$, and $12.5 \mathrm{~cm}$ to produce the twist ratios in $2.93,3.91$, and 4.89. The sweeping face has been used over the entire length of $1800 \mathrm{~mm}$. The twist tape insert is subtracted from cylindrical volume to obtain the required fluid domain. Different types of meshing elements are available to mesh the volume, but tetrahedral/hybrid and T Grid type elements are the best option in case of irregular shapes. The grid generated for the tube fitted with Parabolic-cut twisted tape insert is shown in Figure 2. The boundary conditions and continuum type for the geometry inlet, outlet, walls, and fluid type were specified.

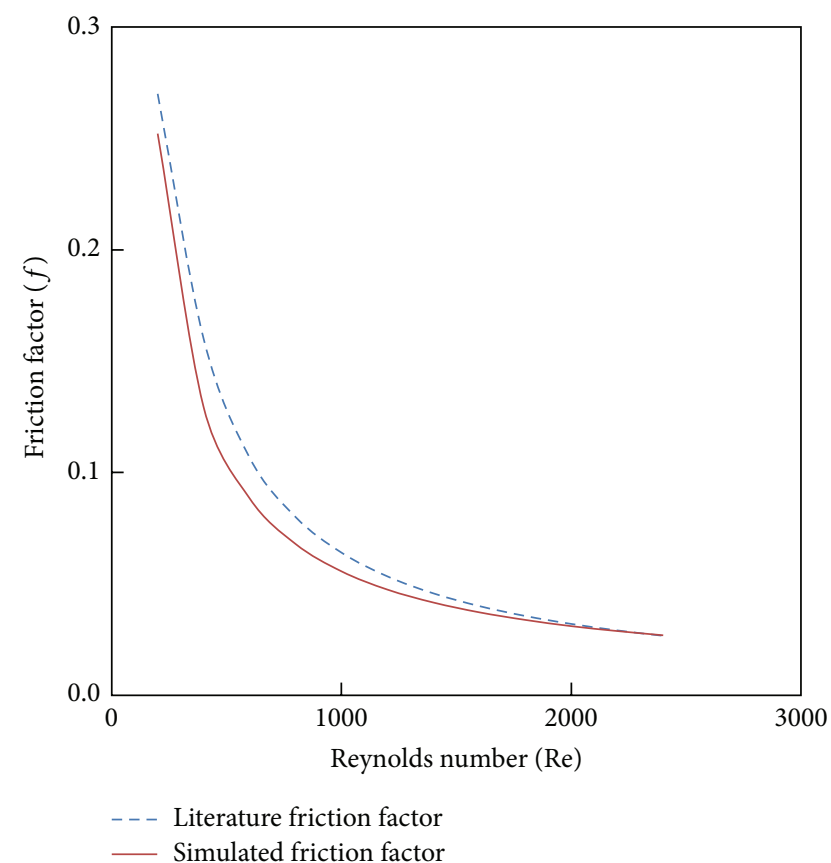

FIGURE 4: Plain tube simulated friction factor versus literature value.

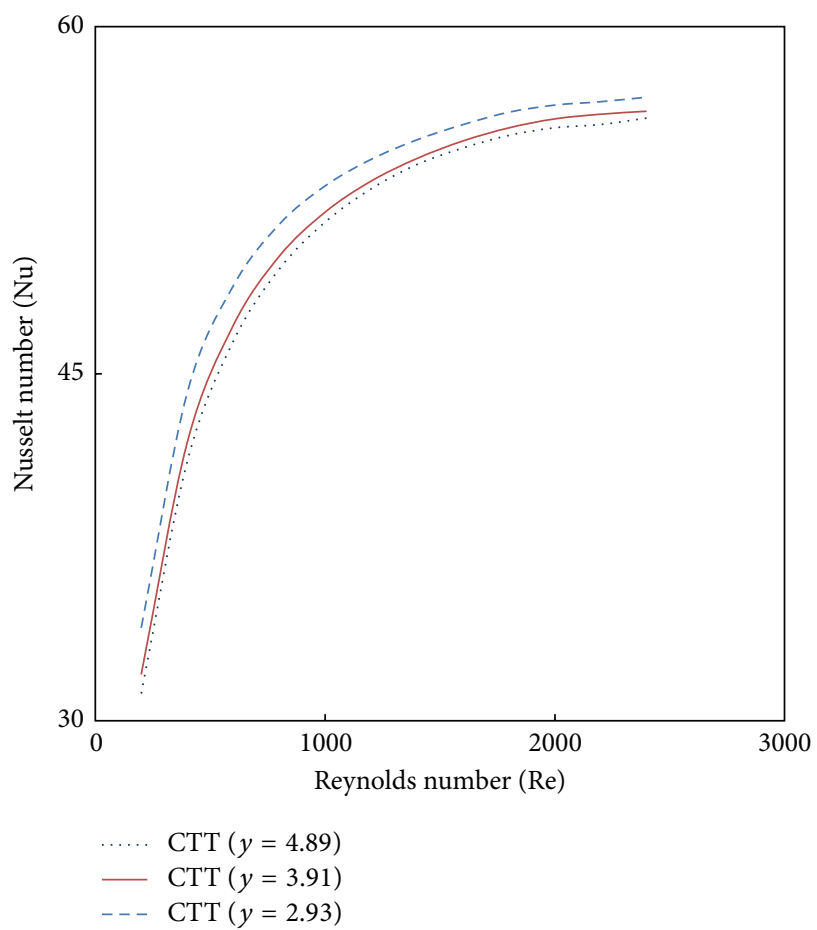

Figure 5: The effect of twist ratio $(y)$ on Nusselt Number.

Subsequently, the meshed volume was exported to FLUENT for simulation.

\subsection{Computational Model}

3.2.1. Assumptions. The nanoparticles in the base fluid may be a single phase fluid with thermal equilibrium and with 


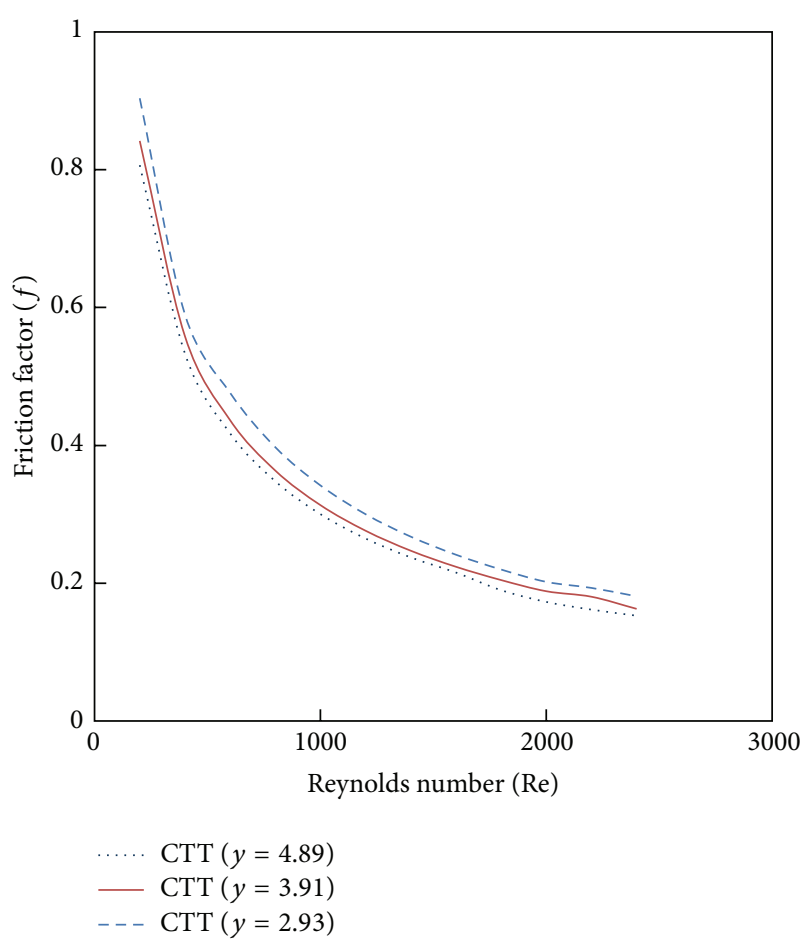

Figure 6: The effect of twist ratio $(y)$ on friction factor.

TABLE 3: Numerical values of the parameters used for simulation.

\begin{tabular}{lc}
\hline Mass flow rate $(\mathrm{Kg} / \mathrm{s})$ & Heat flux $\left(\mathrm{W} / \mathrm{m}^{2}\right)$ \\
\hline 0.00384 & 782.9275132 \\
0.00769 & 1565.855026 \\
0.01153 & 2348.78254 \\
0.01537 & 3131.710053 \\
0.01922 & 3914.637566 \\
0.02306 & 4697.565079 \\
0.02690 & 5480.492592 \\
0.03074 & 6263.420105 \\
0.03459 & 7046.347619 \\
0.03843 & 7829.275132 \\
\hline
\end{tabular}

zero relative velocity between the fluid phase and nanoparticles. These assumptions will exactly reflect the behaviour of nanofluid in engineering problems. The problem was investigated for three-dimensional steady state laminar flow using the following model equations with the numerical values of the mass flow rate and constant heat flux given in Table 3.

3.2.2. Continuity Equation for Incompressible Fluid. Consider the following:

$$
\frac{\partial p}{\partial t}+\nabla \cdot(\rho \vec{v})=S_{m}
$$

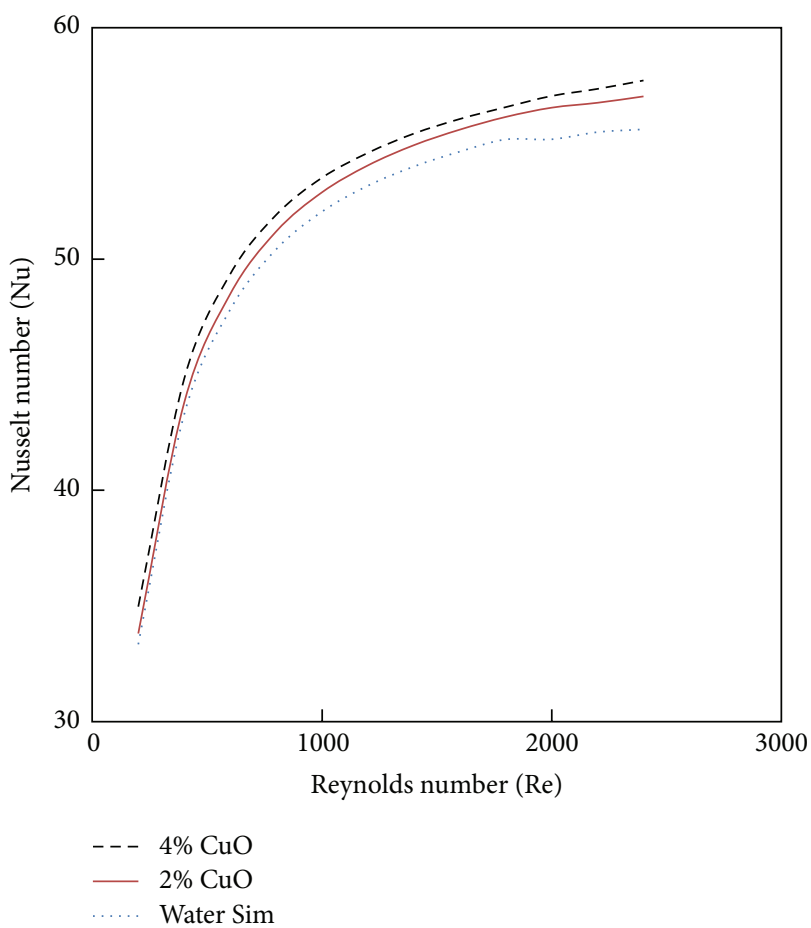

FIGURE 7: The effect of $\mathrm{CuO}$ nanofluid volume concentration on Nusselt number for CCT with twist ratio 2.93.

3.2.3. Conservation of Momentum. Consider the following:

$$
\frac{\partial v}{\partial t}+\rho(\vec{v} \cdot \nabla) \vec{v}=-\nabla p+\rho \bar{g}+\nabla \cdot \tau_{i j}+\vec{F}
$$

3.2.4. Conservation of Energy. Consider the following:

$$
\begin{aligned}
& \rho \frac{\partial}{\partial t}(\rho E)+\nabla \cdot\{\vec{v}(\rho E+\rho)\} \\
& \quad=\nabla \cdot\left\{K_{\mathrm{eff}} \nabla T-\sum h_{i}\left(\vec{\tau}_{\mathrm{eff}} \cdot \vec{v}\right)\right\}+S_{h} .
\end{aligned}
$$

The following equations are used to calculate the Nusselt number $(\mathrm{Nu})$ and the friction factor $(f)$ :

$$
\begin{gathered}
\mathrm{Nu}=\frac{h D}{K}, \\
h=\frac{q}{T_{w}-T_{b}}, \\
f=\frac{64}{\operatorname{Re}}, \\
\operatorname{Re}=\frac{\rho u D}{\mu},
\end{gathered}
$$

where $D$ is the tube diameter, $h$ is the heat transfer coefficient, $k$ is the conductivity of water, $q^{\bullet}$ is the heat flux on the tube, $T_{w}$ is the tube wall temperature, and $T_{b}$ is the bulk temperature of water $T_{b}=\left(T_{0}+T_{i}\right) / 2 . \rho$ is the density, $\mu$ is dynamic viscosity, and $u$ is the water velocity. 


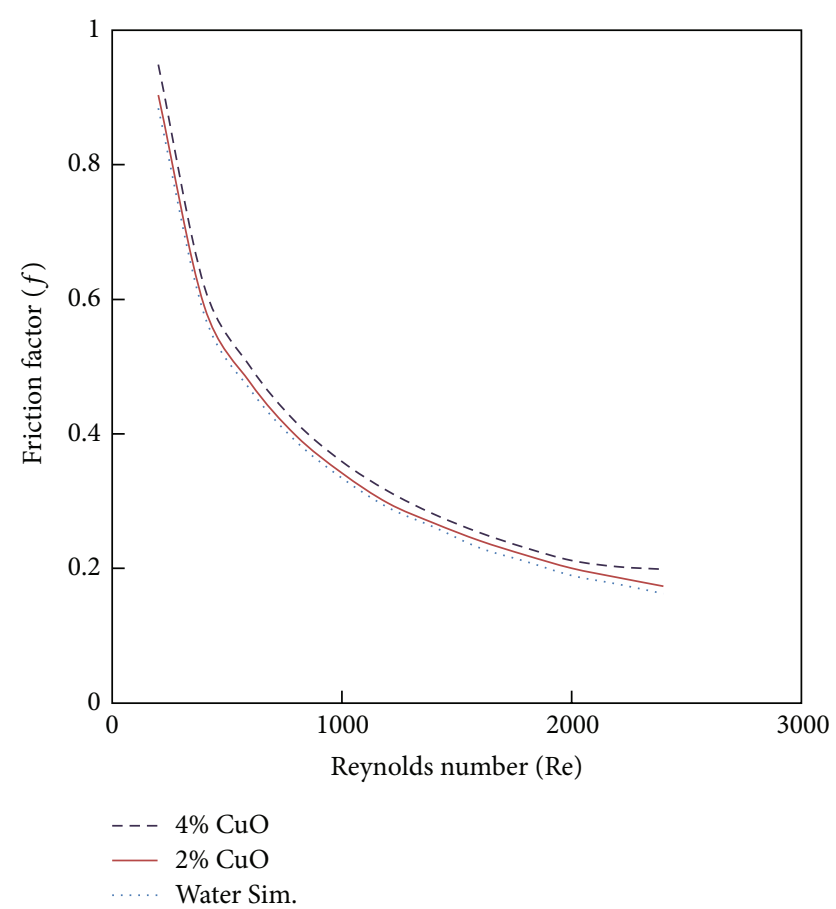

FIGURE 8: The effect of $\mathrm{CuO}$ nanofluid volume concentration on fiction factor for CCT of twist ratio 2.93.

\section{Results and Discussion}

4.1. Grid Independence Test and Model Validation. A grid independence test was tested to evaluate the effects of grid sizes on the simulated results; five mesh volumes were considered at $\mathrm{Re}=2000$ (401226, 532338, 656404, 727890, and 838278). It is observed that all the five mesh volumes have similar results of the Nusselt number with a percentage error of $0.3 \%$. Hence, a domain with mesh volume of 656404 was chosen to reduce the computational time. Computations data of the Nusselt number and friction factor was first performed for water in a plain tube to validate the model against data developed by Stephan and Preußer correlations [22]. Figures 3 and 4 show the variation of Nusselt number and friction factor with Reynolds number for plain tube. Apparently, the present results reasonably agreed well with the available correlations within $\pm 8 \%$ and $\pm 10 \%$ for Nusselt number and friction factor, respectively.

4.2. Effect of Twist Ratio. Variation of simulated Nusselt number and friction factor with Reynolds number for water in the presence of classical twisted tape inserts are illustrated in Figures 5 and 6. It is found that the Nusselt number and friction factor in lower twist ratios are higher than those from higher ratio $(y)$ across the range of Reynolds number. This means that the lower twist ratio leads to higher tangential contact between the swirling flow and the tube surface.

4.3. Effect of Nanofluid Volume Fractions. CuO nanoparticles of $2 \%$ and $4 \%$ volume fraction with different values of Reynolds number are investigated as shown in Figures 7

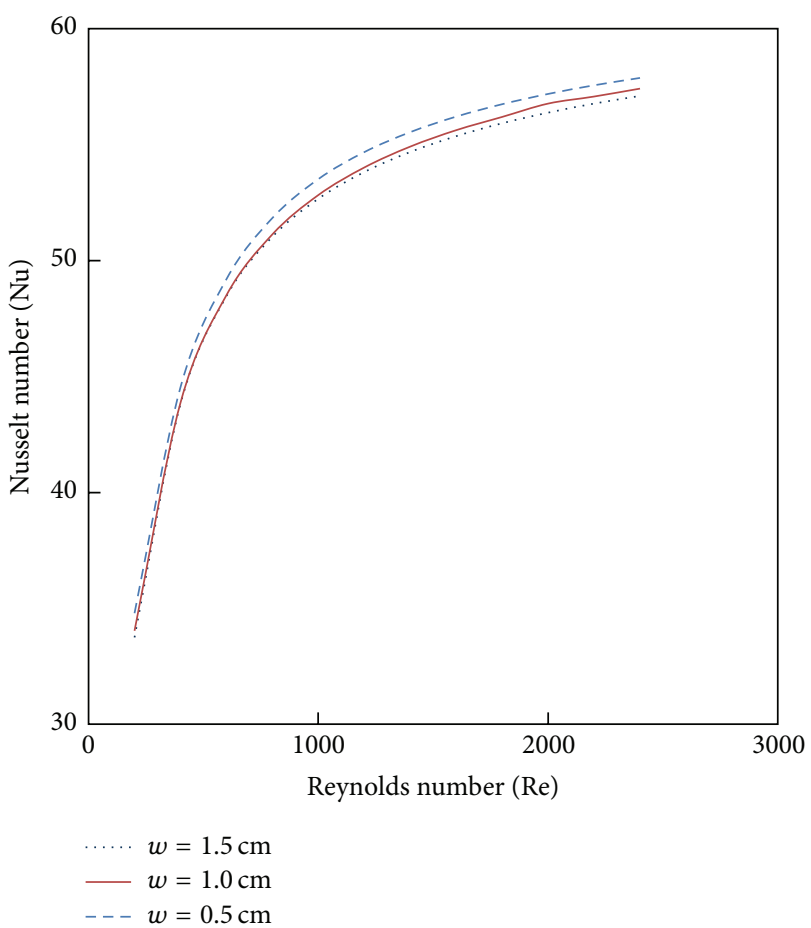

Figure 9: The effect of cut depth $4 \% \mathrm{CuO}$ nanofluid on Nusselt number.

and 8. From Figure 7, it is clearly noted that the Nusselt number is enhanced with increases of volume fraction of nanoparticles. This means that the volume fraction increases the random movements of the particles and enhances the thermal dispersion of the flow. Figure 8 shows the friction factor variation with the Reynolds number for different volume fractions of nanoparticles. It is clearly noted that the wall shear stress increases with the increase of the nanoparticles volume fraction.

4.4. Effect of Twist Tape Configuration. Variation of simulated Nusselt number and friction factor with Reynolds number for the tube fitted Parabolic-cut twist tape with twist ratio $y=$ 2.93 are shown in Figures 9 and 10. It is obvious that the heat transfer and friction factor are increased with decreases of cut depth; this is mainly due to the combined effects of common swirling flow by the twisted tape and turbulence generated by the alternative cuts along the edge of the twisted tape. This effect leads to the destruction of the thermal boundary layer and creating better flow mixing between the fluids at the core and heating wall surface.

Figures 11 and 12 show the effect of the new configuration on heat transfer enhancement and friction factor characteristics. Its show that The parabolic-cut twist tape offers heat transfer enhancement better than the classical one with a penalty on the wall shear stress.

\section{Conclusion}

CFD simulation for the heat transfer augmentation in a circular tube equipped with classical and Parabolic-cut twisted 


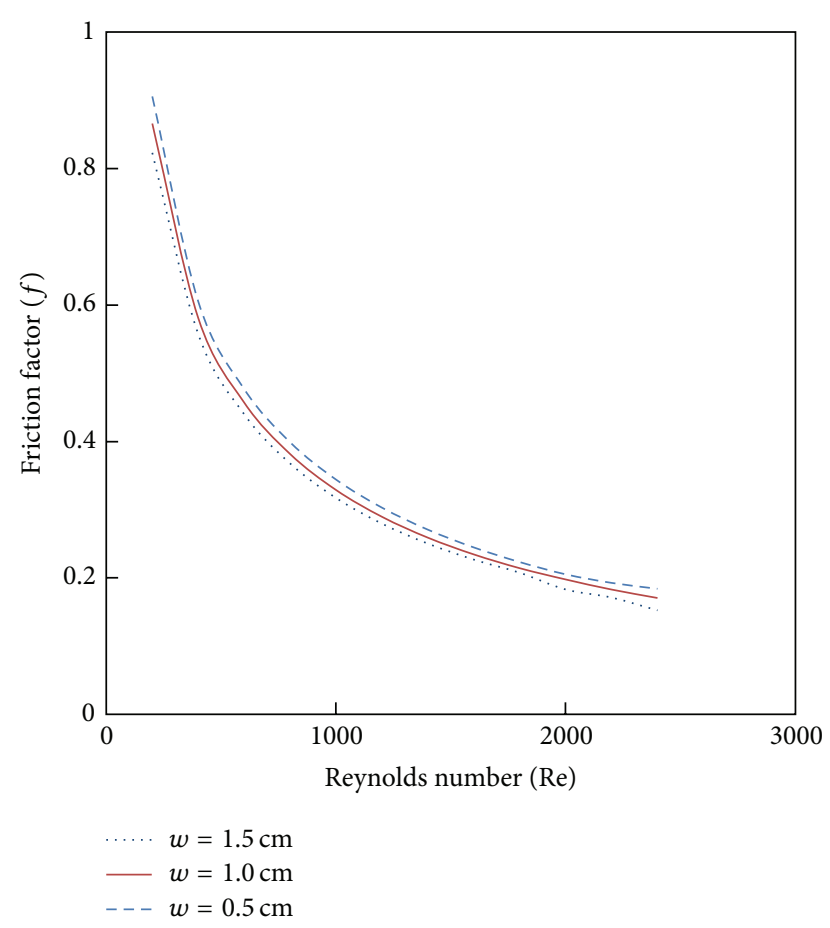

Figure 10: The effect of cut depth with $4 \% \mathrm{CuO}$ nanofluid on friction factor.

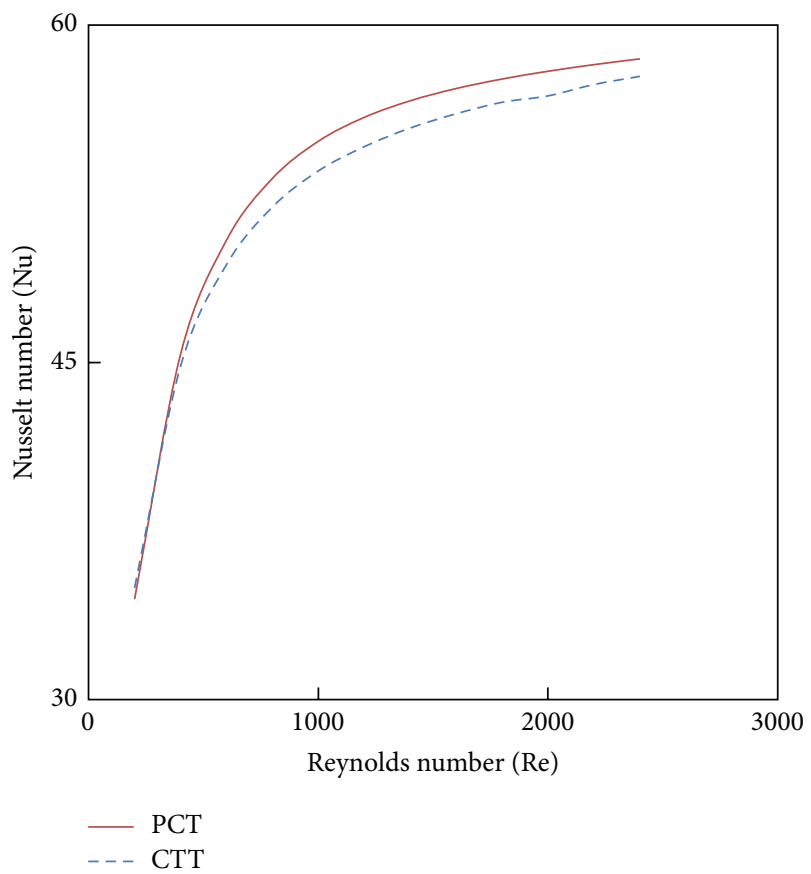

FIGURE 11: The effect of twist configuration with $4 \% \mathrm{CuO}$ nanofluid on Nusselt number.

tape (PCT) for $2 \%$ and $4 \%$ volume fraction of $\mathrm{CuO}$ nanofluid was carried out using FLUENT version 6.3.26. The data obtained by simulation are matching with the literature correlations of plain tube for validation with the discrepancy of less than $\pm 8 \%$ for the Nusselt number and $\pm 10 \%$ for friction factor. The results show that the Nusselt number increased with

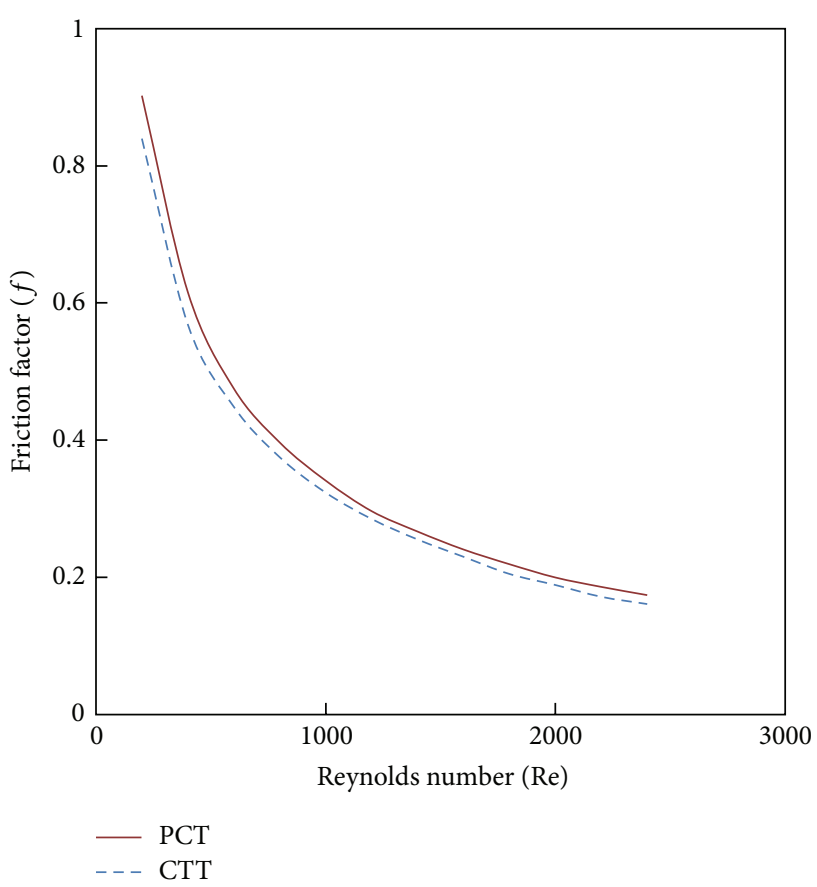

FIGURE 12: The effect of twist configuration with $4 \% \mathrm{CuO}$ nanofluid on friction factor.

the increase of the nanoparticle volume fraction, Reynolds number, and twist tape decreases. The results also revealed that the twist tape with twist ratio $y=2.93$ and cut depth $(w=$ $0.5 \mathrm{~cm})$ was more dominant than those of $(w=1$ and $1.5 \mathrm{~cm})$ for all the Reynolds number. Furthermore, the Parabolic-cut twisted tape (PCT) with $4 \% \mathrm{CuO}$ nanofluid offers about $10 \%$ more enhancement of the Nusselt number with significant increases in friction factor than that of Classical twisted tape.

\section{Nomenclature}

CuO: Copper oxide

Cp: Specific heat of the fluid, J/kg K

$d p: \quad$ Nanoparticle diameter, $\mathrm{nm}$

$E$ : Energy component in energy equation

$F$ : Force component in momentum equation, N

$f$ : $\quad$ Friction factor

$g: \quad$ Acceleration due to gravity, $\mathrm{m} / \mathrm{s}^{2}$

$k_{\text {eff: }}$ Thermal conductivity in energy equation, $\mathrm{W} / \mathrm{m} \mathrm{K}$

$m$ : $\quad$ Mass flow rate of fluid, $\mathrm{kg} / \mathrm{s}$

Re: Reynolds number based on internal diameter of the tube, dimensionless

$\mathrm{Nu}$ : Nusselt number, dimensionless

$p: \quad$ Pressure component in momentum equation, $\mathrm{N} / \mathrm{m}^{2}$

$S_{m}: \quad$ Accumulation of mass, $\mathrm{Kg}$

$S_{h}$ : Accumulation of energy, J

T: $\quad$ Temperature, ${ }^{\circ} \mathrm{C}$

$v$ : Velocity component in momentum equation, $\mathrm{m} / \mathrm{s}$

$y: \quad$ Twist ratio, dimensionless. 


\section{Greek Symbols}

$\rho$ : Density component in governing equations $\vec{\tau}_{\text {eff: }}$ Stress component in momentum equation, $\mathrm{N} / \mathrm{m}^{2}$.

\section{Conflict of Interests}

The authors declare that there is no conflict of interests regarding the publication of this paper.

\section{Acknowledgments}

The authors would like to thank the National University of Malaysia and the Ministry of Higher Education for the financial support (FRGS/1/2013/TK07/UKM/01/1) and DPP2013-114 to carrying out this investigation.

\section{References}

[1] P. Sivashanmugam and P. K. Nagarajan, "Studies on heat transfer and friction factor characteristics of laminar flow through a circular tube fitted with right and left helical screw-tape inserts," Experimental Thermal and Fluid Science, vol. 32, no. 1, pp. 192197, 2007.

[2] M. A. Kedzierski and M. Gong, "Effect of $\mathrm{CuO}$ nanolubricant on R134a pool boiling heat transfer," International Journal of Refrigeration, vol. 32, no. 5, pp. 791-799, 2009.

[3] P. Murugesan, K. Mayilsamy, S. Suresh, and P. S. S. Srinivasan, "Heat transfer and pressure drop characteristics of turbulent flow in a tube fitted with trapezoidal-cut twisted tape insert," International Journal of Academic Research, vol. 1, no. 1, pp. 123128, 2009.

[4] S. Jaisankar, T. K. Radhakrishnan, K. N. Sheeba, and S. Suresh, "Experimental investigation of heat transfer and friction factor characteristics of thermosyphon solar water heater system fitted with spacer at the trailing edge of Left-Right twisted tapes," Energy Conversion and Management, vol. 50, no. 10, pp. 26382649, 2009 .

[5] M. Chandrasekar, S. Suresh, and A. Chandra Bose, "Experimental studies on heat transfer and friction factor characteristics of $\mathrm{Al}_{2} \mathrm{O}_{3}$ /water nanofluid in a circular pipe under laminar flow with wire coil inserts," Experimental Thermal and Fluid Science, vol. 34, no. 2, pp. 122-130, 2010.

[6] L. S. Sundar and K. V. Sharma, "Turbulent heat transfer and friction factor of $\mathrm{Al}_{2} \mathrm{O}_{3}$ Nanofluid in circular tube with twisted tape inserts," International Journal of Heat and Mass Transfer, vol. 53, no. 7-8, pp. 1409-1416, 2010.

[7] S. Eiamsa-ard and P. Promvonge, "Performance assessment in a heat exchanger tube with alternate clockwise and counterclockwise twisted-tape inserts," International Journal of Heat and Mass Transfer, vol. 53, no. 7-8, pp. 1364-1372, 2010.

[8] P. Seemawute and S. Eiamsa-ard, "Thermohydraulics of turbulent flow through a round tube by a peripherally-cut twisted tape with an alternate axis," International Communications in Heat and Mass Transfer, vol. 37, no. 6, pp. 652-659, 2010.

[9] S. Eiamsa-ard, K. Wongcharee, P. Eiamsa-ard, and C. Thianpong, "Heat transfer enhancement in a tube using delta-winglet twisted tape inserts," Applied Thermal Engineering, vol. 30, no. 4, pp. 310-318, 2010.

[10] P. K. Nagarajan, Y. Mukkamala, and P. Sivashanmugam, "Studies on heat transfer and friction factor characteristics of turbulent flow through a micro-finned tube fitted with left-right inserts," Applied Thermal Engineering, vol. 30, no. 13, pp. 1666-1672, 2010.

[11] S. Eiamsa-Ard and P. Promvonge, "Thermal characteristics in round tube fitted with serrated twisted tape," Applied Thermal Engineering, vol. 30, no. 13, pp. 1673-1682, 2010.

[12] S. Eiamsa-ard, P. Seemawute, and K. Wongcharee, "Influences of peripherally-cut twisted tape insert on heat transfer and thermal performance characteristics in laminar and turbulent tube flows," Experimental Thermal and Fluid Science, vol. 34, no. 6, pp. 711-719, 2010.

[13] S. Eiamsa-ard, K. Wongcharee, P. Eiamsa-ard, and C. Thianpong, "Thermohydraulic investigation of turbulent flow through a round tube equipped with twisted tapes consisting of centre wings and alternate-axes," Experimental Thermal and Fluid Science, vol. 34, no. 8, pp. 1151-1161, 2010.

[14] S. Eiamsa-ard, C. Thianpong, P. Eiamsa-ard, and P. Promvonge, "Thermal characteristics in a heat exchanger tube fitted with dual twisted tape elements in tandem," International Communications in Heat and Mass Transfer, vol. 37, no. 1, pp. 39-46, 2010.

[15] K. Wongcharee and S. Eiamsa-ard, "Friction and heat transfer characteristics of laminar swirl flow through the round tubes inserted with alternate clockwise and counter-clockwise twisted-tapes," International Communications in Heat and Mass Transfer, vol. 38, no. 3, pp. 348-352, 2011.

[16] R. Kharat, N. Bhardwaj, and R. S. Jha, "Development of heat transfer coefficient correlation for concentric helical coil heat exchanger," International Journal of Thermal Sciences, vol. 48, no. 12, pp. 2300-2308, 2009.

[17] G. Pathipakka and P. Sivashanmugam, "Heat transfer behaviour of nanofluids in a uniformly heated circular tube fitted with helical inserts in laminar flow," Superlattices and Microstructures, vol. 47, no. 2, pp. 349-360, 2010.

[18] S. D. Salman, A. A. H. Kadhum, M. S. Takriff, and A. B. Mohamad, "CFD simulation of heat transfer and friction factor augmentation in a circular tube fitted with elliptic-cut twisted tape inserts," Mathematical Problems in Engineering, vol. 2013, Article ID 163839, 7 pages, 2013.

[19] S. D. Salman, A. A. H. Kadhum, M. S. Takriff, and A. B. Mohamad, "Numerical Investigation of Heat transfer and friction factor characteristics in a circular tube fitted with V-cut twisted tape inserts," The Scientific World Journal, vol. 2013, Article ID 492762, 8 pages, 2013.

[20] R. S. Vajjha and D. K. Das, "Experimental determination of thermal conductivity of three nanofluids and development of new correlations," International Journal of Heat and Mass Transfer, vol. 52, no. 21-22, pp. 4675-4682, 2009.

[21] M. Corcione, "Heat transfer features of buoyancy-driven nanofluids inside rectangular enclosures differentially heated at the sidewalls," International Journal of Thermal Sciences, vol. 49, no. 9, pp. 1536-1546, 2010.

[22] K. Stephan and P. Preußer, "Wärmeübergang und maximale Wärmestromdichte beim Behältersieden binärer und ternärer Flüssigkeitsgemische," Chemie Ingenieur Technik, vol. 51, no. 1, p. 37, 1979. 


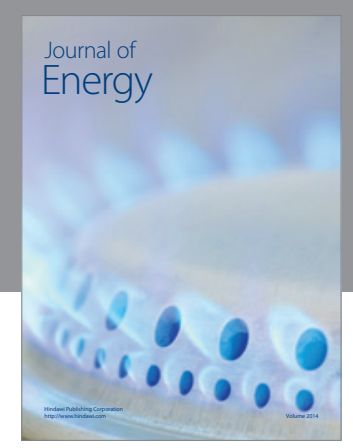

Journal of

Industrial Engineering
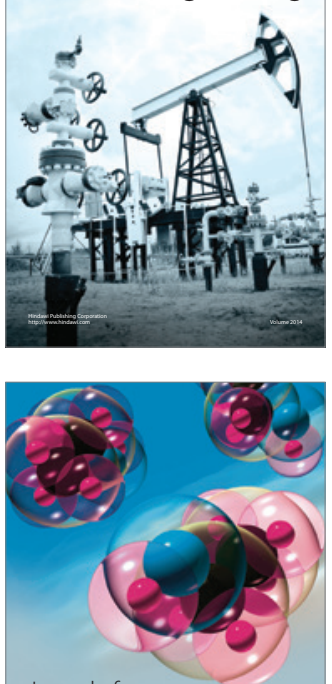

Fuels
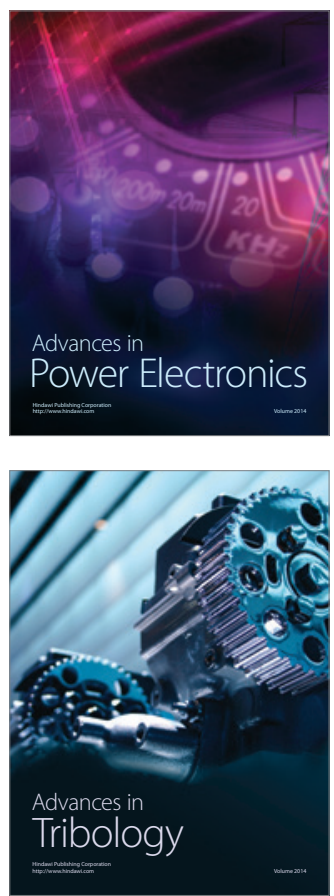

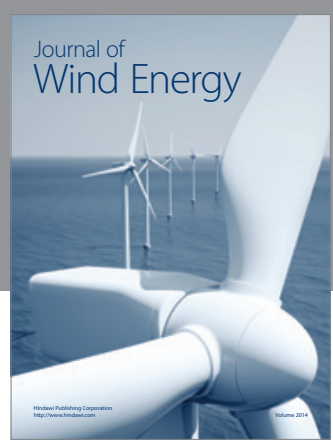

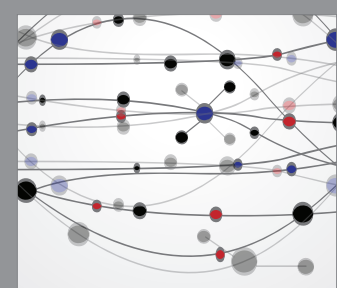

The Scientific World Journal

Submit your manuscripts at http://www.hindawi.com

Journal of

Structures
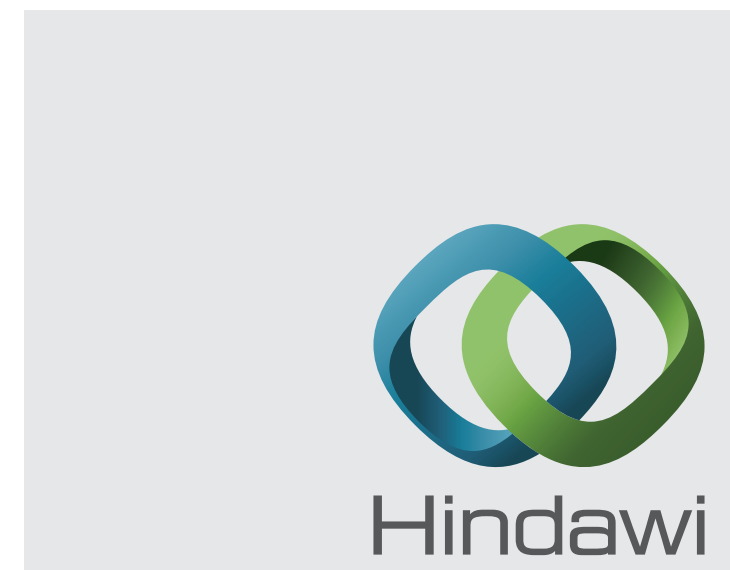

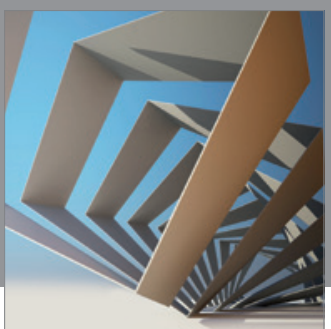

Rotating

Machinery
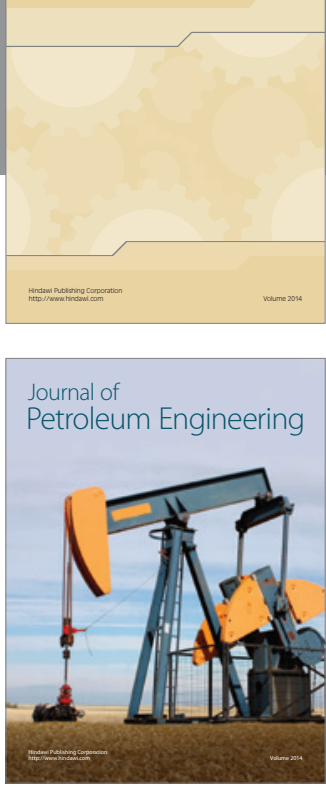

Journal of

Solar Energy
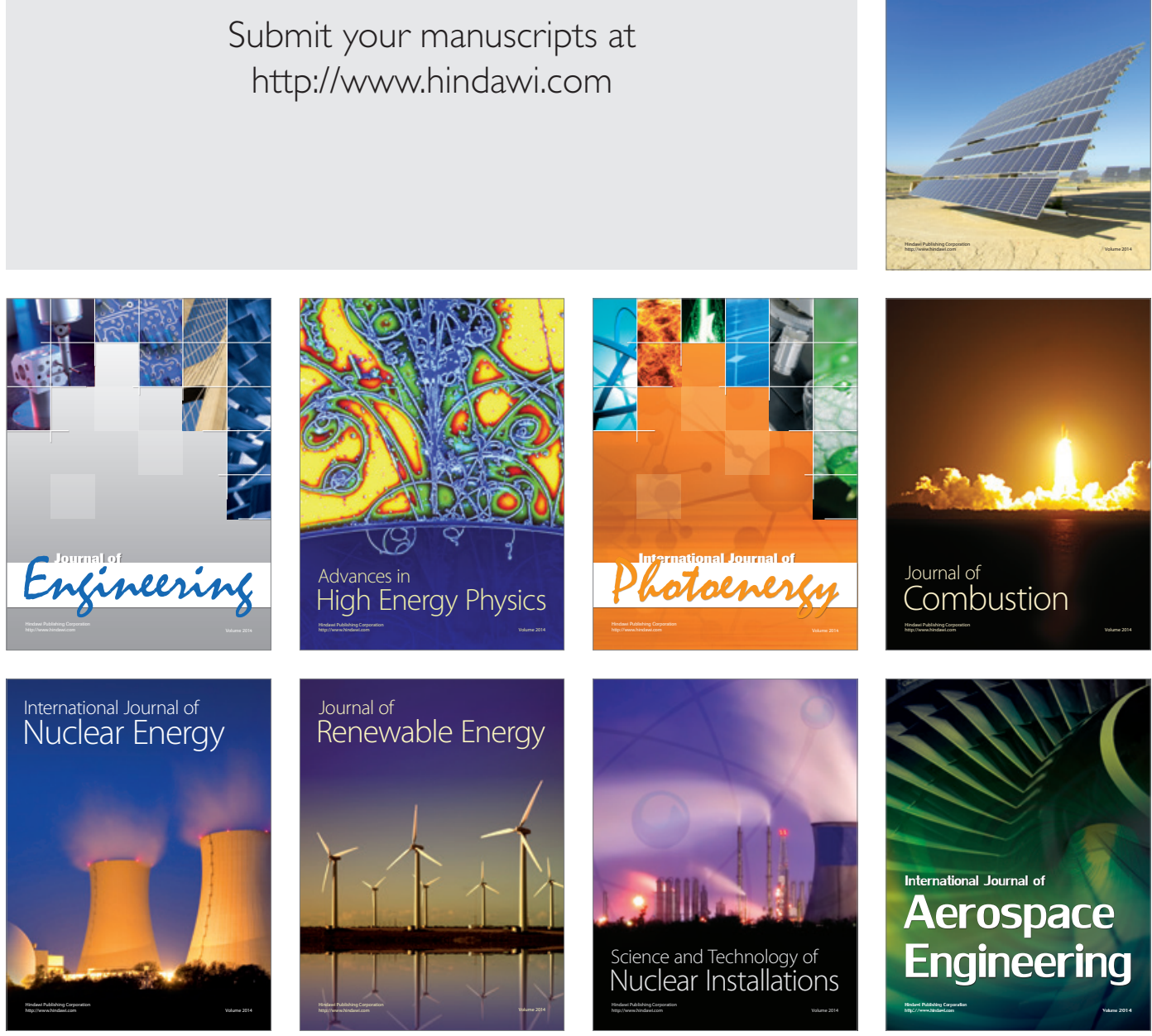